\title{
Solitary fibrous tumours of the lacrimal sac: A case study and comparison
}

\author{
Lee Chun Yun Caroline ${ }^{1 *}$, Heng Li Wei ${ }^{2}$, Clarence Teo Hai Yi ${ }^{3}$, Bundele Manish Mahadeorao ${ }^{3}$, Amit Karandikar ${ }^{4}$, Siow Jin Keat ${ }^{1}$, Fu Weizhong \\ Ernest $^{1}$, Li Hao ${ }^{1}$ and Lim Ming Yann ${ }^{1}$
}

${ }^{1}$ Department of Otorhinolaryngology, Tan Tock Seng Hospital, Singapore

${ }^{2}$ Department of Ophthalmology, Tan Tock Seng Hospital, Singapore

${ }^{3}$ Department of Pathology, Tan Tock Seng Hospital, Singapore

${ }^{4}$ Department of Diagnostic Radiology, Tan Tock Seng Hospital, Singapore

\begin{abstract}
Solitary fibrous tumours are rare benign spindle cell neoplasms that arise uncommonly in the lacrimal sac but can occur in numerous other locations. Due to their rarity, heterogeneity of clinical presentations and histological appearances, they may easily be missed or misdiagnosed. In this paper we report a case of this rare tumour
\end{abstract} and compare our findings with the other 4 available cases in the English literature

\section{Case report}

A 62 year old Chinese male presented with a 3-month history of right epiphora and blurring of vision. On examination, right eye hyperglobus (Figure 1) was noted and pupillary examination showed a relative afferent pupillary defect. On palpation there was firmness over the right lower eyelid. Flexible nasendoscopy was unremarkable and no mass was noted in the inferior meatus. MRI and CT orbits revealed a $3.6 \mathrm{~cm}$ mass centred in the right lacrimal sac with extension into the proximal right nasolacrimal duct. Mass effect and indentation of medial aspect of right globe was noted, displacing it superolaterally, and there was no signal abnormality or enhancement in adjacent orbital fat (Figures 3-5). He underwent an endoscopic biopsy and histology showed a spindle cell tumour (Figure 2) with immunohistochemical staining positive for CD34. Decision was made for surgical resection of the tumour. Patient underwent a right lateral rhinotomy and excision of right lacrimal sac tumour. Intraoperatively, a $3 \mathrm{~cm}$ right lacrimal sac tumour was noted with a clear plane between tumour and right periorbita laterally. The tumour did not breach the skull base (Figure $6 \mathrm{a}$ and $6 \mathrm{~b})$.

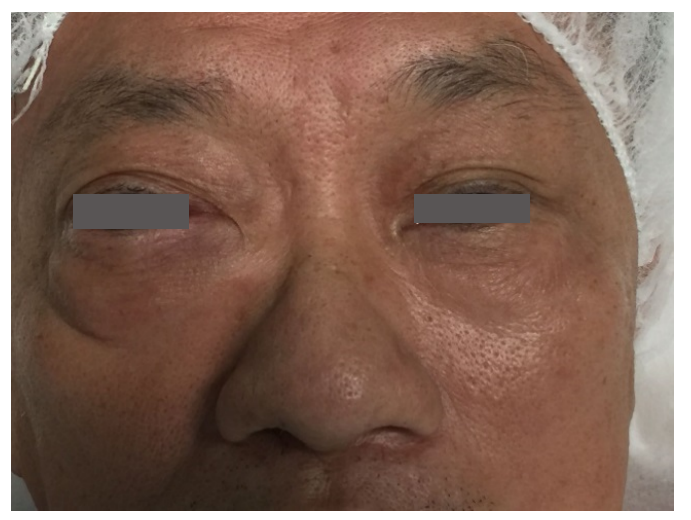

Figure 1: Clinical photo showing right hyperglobus

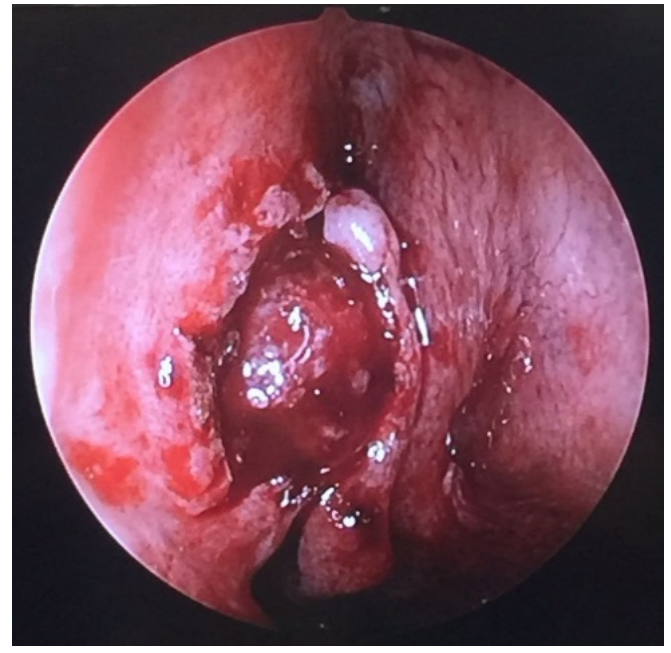

Figure 2: Endoscopic picture of right lacrimal sac tumour

Histopathology revealed a cellular spindle cell lesion featuring fascicles and storiform architecture with occasional foci of staghorn vessels, perivascular hyalinization and keloidal collagen bundles. There was mild to moderate atypia, focal necrosis and a mitoses rate up to 6-7 per $10 \mathrm{HPF}$.

Postoperatively the patient's hyperglobus improved (Figure 7), but he developed a right ectropion which was surgically corrected at a later date. The patient was last reviewed 16 months post-operatively, and flexible nasendoscopy showed no recurrence (Figure 8).

*Correspondenceto: LeeChun Yun Caroline, DepartmentofOtorhinolaryngology, Tan Tock Seng Hospital, Singapore, E-mail: caroline.lee@mohh.com.sg

Received: May 05, 2018; Accepted: May 21, 2018; Published: May 24, 2018 


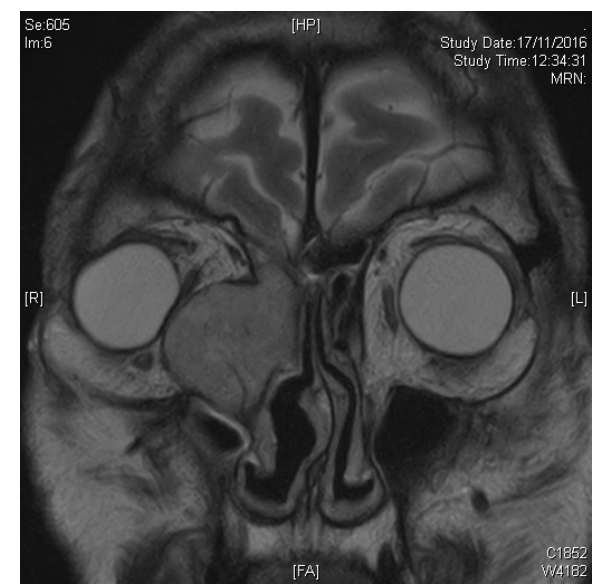

Figure 3. MRI T2 weight image of right lacrimal sac tumour, coronal cut

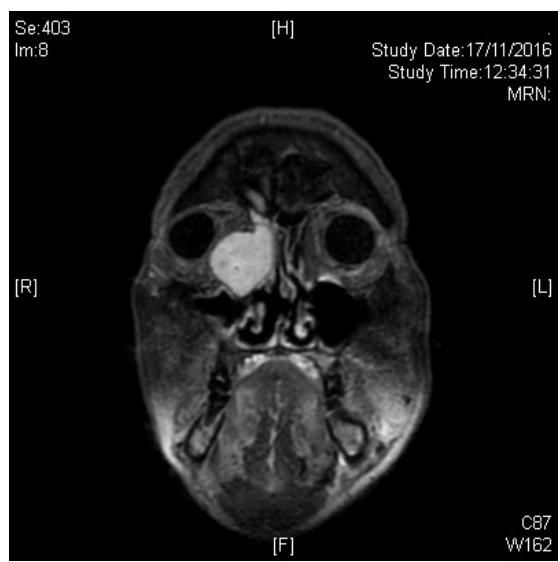

Figure 4. MRI T1 weight image of right lacrimal sac tumour, coronal cut

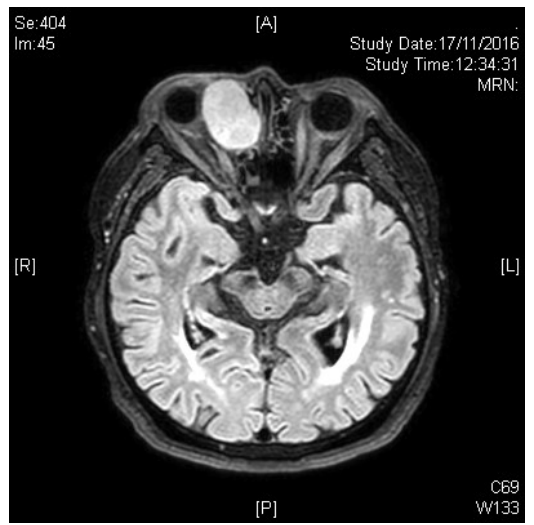

Figure 5: MRI T1 weight image of right lacrimal sac tumour, axial cut
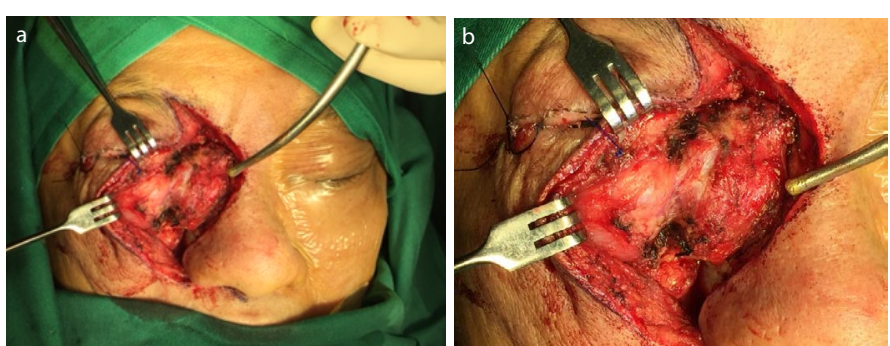

Figures 6a \& 6b: Intraoperative photo of right lacrimal sac tumour 


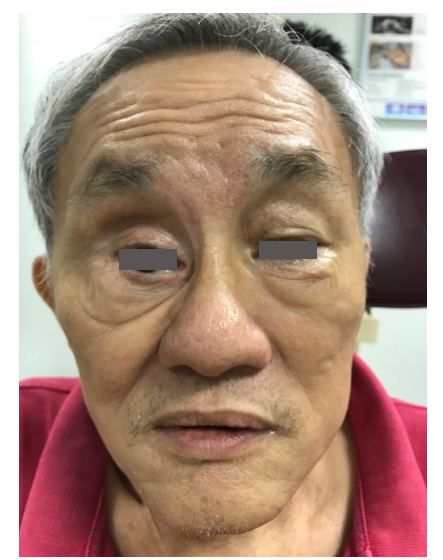

Figure 7. Clinical photo showing improvement of right hyperglobus post-operatively

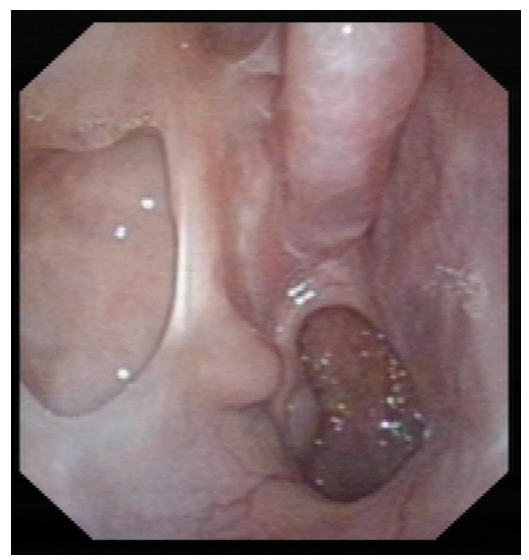

Figure 8: Endoscopic photo of right nasal cavity 16 months post-op, showing no recurrence of tumour

\section{Discussion}

Solitary fibrous tumours (SFT) are a rare benign spindle cell neoplasm of mesenchymal origin. It was initially described in the pleura but now is recognized anywhere in the body including soft tissue and viscera of the abdomen, pelvis and trunk. It can also arise in the head and neck region, which represents $6 \%$ of all SFTs [1]. The sinonasal tract and orbit were the most common extracranial head and neck sites involved, accounting for $30 \%$ and $25 \%$ of head and neck SFTs [1].

To the best of our knowledge, we have found 4 case reports of solitary fibrous tumour in the lacrimal sac between 1999 and 2017 [24]. Table 1 lists the clinical features and Table 2 lists the histological findings by case.

SFTs may present across varied age groups - in these five patients (including our case) the median age at diagnosis was 44 years old with a range of 23 to 67 years. Out of the 5 patients, 2 were male and 3 were female. Due to the rarity of these tumours it is difficult to conclude if there is a gender predilection. However, based on literature of other SFTs, no gender predominance was noted [5].

Three cases presented with epiphora, four cases presented with a medial canthal mass, while in our case both were present. In the cases presenting with a mass, they had a prolonged history ranging from 3 to 12 months in duration, suggesting that this tumour is slow growing. Recurrent dacryocystitis was not a consistent feature across these cases.
The diagnosis of SFTs is challenging as it does not have distinct histopathological features [2]. Microscopically, SFTs typically consist of ovoid to spindle cells that are haphazardly arranged with varying cellular densities in admixture with stromal collagen bundles [1]. However due to histological diversity, SFTs can mimic other tumours such as mesotheliomas and sarcomas [6,7]. Hence immunochemical staining has proven useful in establishing the diagnosis. Comparing the 4 cases of lacrimal sac SFTs, immunohistochemistry was positive for CD-34 and vimetin in all cases and negative for S-100 protein and desmin. Mitoses do not commonly exceed 3/10 HPF [8].

A multi-institutional retrospective case series of 88 cases of head and neck SFTs, analysed that size and mitoses rate of $>4 / 10$ HPF were associated with risk of recurrence [1]. In cases of lacrimal sac SFTs reported so far, mitoses were not commonly found, however, in our case mitoses rate of 6-7/10 HPF was noted. Based on the few reported cases alone, it is difficult to predict the prognosis of lacrimal sac SFTs, however in all cases reported thus far, the patient has remained recurrence free up to 1 year after complete resection [2].

Tumour recurrence is also associated with incomplete excision as reported in the first 2 cases of lacrimal sac SFTs, in which their patients had undergone excision 4 months to 7 years prior to re-presenting. In our case, histology showed that the tumour extended to the superior margin of the specimen, which corresponds to the skull base. However intra-operatively, the tumour was noted to be abutting but not breaching the skull base. In addition, further drilling of the skull base was done. Our patient has been recurrence free up to 16 months post-op. 
Table 1. Clinical features of lacrimal sac solitary fibrous tumours

\begin{tabular}{|c|c|c|c|c|}
\hline Authour & Rumelt 2003 & Kurdi 2014 & Woo (case 1) & Woo (case 2) \\
\hline Age (years) & 67 & 44 & 23 & 34 \\
\hline Gender & Male & Female & Male & Female \\
\hline $\begin{array}{c}\text { Presenting } \\
\text { Symptoms }\end{array}$ & Epiphora & $\begin{array}{c}\text { Epiphora } \\
\text { Medial canthal mass }\end{array}$ & Medial canthal mass & Medial canthal mass \\
$\begin{array}{c}\text { Blurring of vision } \\
\text { Medial canthal mass }\end{array}$
\end{tabular}

Table 2. Histological and immunohistochemical features of lacrimal sac solitary fibrous tumours

\begin{tabular}{|c|c|c|c|c|c|}
\hline Authour & Rumelt 2003 & Kurdi 2014 & Woo 1999 (case 1) & Woo 1999 (case 2) & Lee 2018 \\
\hline Mitoses & No mitotic activity & No mitotic activity & Low mitotic activity & Low mitotic activity & Mitotic rate 6-7/10 HPF \\
\hline Necrosis & Absent & Absent & Not reported & Not reported & Present $(<5 \%)$ \\
\hline Margins & $\begin{array}{l}\text { Clear (tumour within the sac } \\
\text { submucosa) }\end{array}$ & Not reported & Clear & Clear & $\begin{array}{l}\text { Tumour extended to superior } \\
\text { margin (skull base) }\end{array}$ \\
\hline CD-34 & Positive & Positive & Positive & Positive & Not available \\
\hline Vimentin & Positive & Positive & Positive & Positive & Not available \\
\hline S-100 protein & Negative & Negative & Negative & Negative & Not available \\
\hline Desmin & Negative & Negative & Negative & Negative & Not available \\
\hline
\end{tabular}

$\mathrm{HPF}=$ high powered field

\section{References}

1. Smith SC, Gooding WE, Elkins M, Patel RM, Harms PW, et al. (2017) Solitary fibrous tumors of the head and neck: a multi-institutional clinicopathologic study. Am J Surg Pathol 41: 1642-1656. [Crossref]

2. Rumelt S, Kassif Y, Cohen I, Rehany U (2003) A rare solitary fibrous tumour of the lacrimal sac presenting as acquired nasolacrimal duct obstruction. Eye (Lond) 17: 429431. [Crossref]

3. Kurdi M, Allen L, Wehrli B, Chakrabarti S (2014) Solitary fibrous tumour of the lacrimal sac presenting with recurrent dacryocystitis. Can J Ophthalmol 49: e108-110. [Crossref]
4. Woo KI, Suh YL, Kim YD (1999) Solitary fibrous tumour of the lacrimal sac. Ophthalmic Plast Reconstr Surg 15: 450-453. [Crossref]

5. Vogels RJ, Vlenterie M, Versleijen-Jonkers YM, Ruijter E, Bekers EM, et al. (2014) Solitary fibrous tumor - clinicopathologic, immunohistochemical and molecular analysis of 28 cases. Diagn Pathol 9:224. [Crossref]

6. de Perrot M, Fischer S, Bründler MA, Sekine Y, Keshavjee S (2002) Solitary fibrous tumors of the pleura. Ann Thorac Surg 74: 285-293. [Crossref]

7. Fisher C (2011) Immunohistochemistry in diagnosis of soft tissue tumours Histopathology 58: 1001-1012. [Crossref]

8. Kurdi M, Allen L, Wehrli B, Chakrabarti S (2014) Solitary fibrous tumour of the lacrima sac presenting with recurrent dacryocystitis. Can J Ophthalmol 49: e108-110. [Crossref]

Copyright: $@ 2018$ Caroline LCY. This is an open-access article distributed under the terms of the Creative Commons Attribution License, which permits unrestricted use, distribution, and reproduction in any medium, provided the original author and source are credited. 